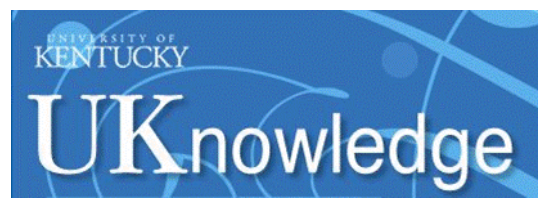

University of Kentucky

UKnowledge

\title{
Impact of the Affordable Care Act on Colorectal Cancer Screening, Incidence, and Survival in Kentucky
}

Tong Gan

University of Kentucky, tong.gan@uky.edu

Heather F. Sinner

University of Kentucky, heather.frohman@uky.edu

Samuel C. Walling

University of Kentucky, scwa222@uky.edu

Quan Chen

University of Kentucky, quan.chen@uky.edu

Bin Huang

University of Kentucky, bhuan0@uky.edu

See next page for additional authors

Follow this and additional works at: https://uknowledge.uky.edu/surgery_facpub

Part of the Bioinformatics Commons, Biostatistics Commons, Oncology Commons, and the Surgery

Commons

Right click to open a feedback form in a new tab to let us know how this document benefits you.

\section{Repository Citation}

Gan, Tong; Sinner, Heather F.; Walling, Samuel C.; Chen, Quan; Huang, Bin; Tucker, Thomas C.; Patel, Jitesh A.; Evers, B. Mark; and Bhakta, Avinash S., "Impact of the Affordable Care Act on Colorectal Cancer Screening, Incidence, and Survival in Kentucky" (2019). Surgery Faculty Publications. 34.

https://uknowledge.uky.edu/surgery_facpub/34

This Article is brought to you for free and open access by the Surgery at UKnowledge. It has been accepted for inclusion in Surgery Faculty Publications by an authorized administrator of UKnowledge. For more information, please contact UKnowledge@lsv.uky.edu. 
Impact of the Affordable Care Act on Colorectal Cancer Screening, Incidence, and Survival in Kentucky

\section{Digital Object Identifier (DOI)}

https://doi.org/10.1016/j.jamcollsurg.2018.12.035

\section{Notes/Citation Information}

Published in Journal of the American College of Surgeons, v. 228, issue 4, p. 342-353.

(c) 2019 Published by Elsevier Inc. on behalf of the American College of Surgeons

(C) 2019 This manuscript version is made available under the CC-BY-NC-ND 4.0 license

http://creativecommons.org/licenses/by-nc-nd/4.0/

\section{Authors}

Tong Gan, Heather F. Sinner, Samuel C. Walling, Quan Chen, Bin Huang, Thomas C. Tucker, Jitesh A. Patel, B. Mark Evers, and Avinash S. Bhakta 
Impact of the Affordable Care Act on Colorectal Cancer Screening, Incidence, and Survival in Kentucky

Tong Gan, MD ${ }^{1,2}$, Heather F Sinner, MD ${ }^{1,2}$, Samuel C Walling, MD ${ }^{1}$, Quan Chen, DrPH ${ }^{2,3}$, Bin Huang, DrPH ${ }^{2,3}$, Tom C Tucker, $\mathrm{PhD}^{2}$, Jitesh A Patel, MD, FACS ${ }^{1,2}$, B Mark Evers, MD, FACS $^{1,2}$, Avinash S Bhakta, MD ${ }^{1,2}$

${ }^{1}$ Department of Surgery, University of Kentucky Medical Center, Lexington, KY

${ }^{2}$ Markey Cancer Center, University of Kentucky Medical Center, Lexington, KY

${ }^{3}$ Biostatistics and Bioinformatics Shared Resource Facility, Markey Cancer Center, Lexington, KY

\section{Disclosure Information: Nothing to disclose.}

Support: Data collection activities of the Kentucky Cancer Registry are supported by the National Cancer Institute Surveillance Epidemiology and End Results Program (NCI HHSN26100001), and the Center for Disease Control and Prevention National Program of Cancer Registries (CDC U58 DP005400). This study was also supported by the Markey Cancer Center Support Grant (NCI P30 CA177558) and T32 NIH Training Grant (T32CA160003). The Center for Clinical and Translational Sciences is funded through the NIH National Center for Advancing Translational Sciences (UL1TR001998).

Disclaimer: This article is solely the responsibility of the authors and does not necessarily represent the official views of the grant-funding agencies.

Presented at the Southern Surgical Association 130th Annual Meeting, Palm Beach, FL, December 2018. 
Correspondence address:

Avinash Bhakta, MD

Assistant Professor of Surgery

Department of Surgery

University of Kentucky

800 Rose Street, C-246

Lexington, KY 40536

Phone: (859) 323-6162

Fax: (859) 257-8934

Email: avinash.bhakta@uky.edu

BRIEF TITLE: Affordable Care Act and Colorectal Cancer Screening 


\section{ABSTRACT}

Background: Kentucky ranks first in the US in cancer incidence and mortality. Compounded by high poverty levels and a high rate of medically uninsured, cancer rates are even worse in Appalachian Kentucky. Being one of the first states to adopt the Affordable Care Act (ACA) Medicaid expansion, insurance coverage markedly increased for Kentucky residents. The purpose of our study was to determine the impact of Medicaid expansion on colorectal cancer (CRC) screening, diagnosis, and survival in Kentucky.

Study Design: The Kentucky Cabinet for Health and Family Services and the Kentucky Cancer Registry were queried for individuals ( $\geq 20$ years) undergoing CRC screening (per US Preventative Services Task-Force) or diagnosed with primary invasive CRC from January 1, 2011 to December 31, 2016. CRC screening rates, incidence, and survival were compared before (2011-2013) and after (2014-2016) ACA implementation.

Results: CRC screening was performed in 930,176 individuals and 11,441 new CRCs were diagnosed from 2011-2016. CRC screening increased substantially for Medicaid patients after ACA implementation $(+230 \%, \mathrm{p}<0.001)$, with a higher increase of screening among the Appalachian $(+44 \%)$ compared with the non-Appalachian $(+22 \%, \mathrm{p}<0.01)$ population. $\mathrm{CRC}$ incidence was increased after ACA implementation in individuals with Medicaid coverage $(+6.7 \%, \mathrm{p}<0.001)$. Additionally, the proportion of early stage CRC (stage I/II) increased by $9.3 \%$ for Appalachians ( $\mathrm{p}=0.09)$, while there was little change for non-Appalachians $(-1.5 \%, \mathrm{p}=0.60)$. CRC survival was improved after ACA implementation $(\mathrm{HR}=0.73, \mathrm{p}<0.01)$, particularly in the Appalachian population with Medicaid Coverage. 
Conclusions: Implementation of Medicaid expansion led to a significant increase in CRC screening, CRC diagnoses, and overall survival in CRC patients with Medicaid, with an even more profound impact in the Appalachian population.

KEYWORDS: Medicaid expansion; Appalachia Kentucky; colorectal cancer

\author{
Abbreviations: \\ CRC: Colorectal cancer \\ ACA: Affordable Care Act \\ FPL: Federal Poverty Level \\ KHFS: Kentucky Cabinet for Health and Family Services \\ KCR: Kentucky Cancer Registry
}




\section{INTRODUCTION}

Kentucky ranks first nationally in incidence and mortality of all site cancers. ${ }^{1,2}$ The Appalachian region of Kentucky heavily contributes to these poor outcomes, where cancer surpasses heart disease as the leading cause of death. ${ }^{2,3}$ The etiology of the disproportionately high cancer rate is multifaceted, but a major factor is the distressed socioeconomic status in Kentucky. ${ }^{2}$ For the past decade, Kentucky maintained the fifth highest poverty rate in the nation. ${ }^{4}$ Even worse, Appalachian Kentucky has the highest poverty rate in the nation at an astounding 1.7 times the national average. Of the 54 counties in Appalachia, 38 counties are economically distressed, or ranks in the bottom $10 \%$ of all US counties. ${ }^{5}$

High poverty levels left a large portion of the Kentucky population uninsured and subsequently unable to seek preventative care. ${ }^{2,6-8}$ The Medicaid Expansion of the Patient Protection and Affordable Care Act (ACA) was incredibly successful in reducing the uninsured rate in Kentucky. ${ }^{9}$ The expansion, enacted in 2014 , provided Medicaid coverage to those at $138 \%$ of the federal poverty level (FPL). Being one of the first two states to implement ACA, uninsured rates dropped in Kentucky by more than half from $13.6 \%$ pre-ACA to $6.1 \%$ two years post-ACA. At the same time, the national uninsured rate dropped from $14.7 \%$ to $9.4 \%$. Medicaid Expansion in the neighboring state of Illinois had a slightly smaller impact; its uninsured rate dropped from $12.9 \%$ to $7.0 \%$. Conversely, Tennessee, a state that did not expand Medicaid, experienced a modest decrease in the uninsured rate (from $13.8 \%$ to $10.2 \%$ ). The population most impacted by the expansion of Medicaid was those under $138 \%$ of national poverty level, which demonstrated a nearly threefold drop in the rate of uninsured individuals (from $25.0 \%$ to $9.4 \%$ ). ${ }^{10}$ 
When looking specifically at colorectal cancer (CRC), Kentucky ranks first nationwide for incidence $(50.0$ cases per 100,000$)$ and fifth for mortality $(17.2$ deaths per 100,000$) .{ }^{1,2}$ As expected, Appalachian Kentucky has even higher incidence (55.1 cases per 100,000) and mortality (20.2 deaths per 100,000). ${ }^{2}$ Screening for CRC has been demonstrated to significantly decrease incidence and mortality. ${ }^{11,12}$ The US Preventative Services Task Force recommended screening for those beginning at the age of 50, with one of the following tests: high-sensitivity fecal occult blood testing annually, sigmoidoscopy every 5 years, or colonoscopy every 10 years. ${ }^{13}$ In the past, Kentucky has reported low rates of CRC screening. In 1999, only $34.7 \%$ of the Kentucky population received CRC screening of any type, ranking $49^{\text {th }}$ in the nation. ${ }^{14}$ These results prompted several state-wide screening initiatives including the establishment of the Kentucky Colon Cancer Screening Program and the Kentucky Colon Cancer Screening Advisory Committee in 2002. As a result, CRC screening rates improved to $65.9 \%$ in those 50 years or older in 2012. However, CRC screening rates, although improved in western and central Kentucky, remained low in eastern Appalachian Kentucky. ${ }^{15,16}$ The purpose of this study is to evaluate the effect of ACA Medicaid expansion on CRC screening, incidence, and survival in the Kentucky population with a particular focus on Appalachian Kentucky.

\section{METHODS}

\section{Data Sources}

Kentucky CRC screening, incidence and outcomes data were obtained from two distinct databases. CRC screening data was obtained from the Kentucky Hospital Discharge Database, which resided in the Kentucky Cabinet for Health and Family Services (KHFS). Ethical approval for the utilization of this database was obtained from the University of Kentucky's Office of 
Research Integrity Institutional Review Board. The sample population included all patients older than 20 years old who underwent CRC screening from January 1, 2011 to December 31, 2016. Each screening occurrence was captured through the CPT code involving either screening or diagnostic colonoscopy, sigmoidoscopy, guaiac based fecal occult test, fecal immunochemical test or fecal DNA test. Each case was then confirmed with the ICD ( 9 and 10) code for screening visits, allowing for the capture of recoded endoscopic procedures from screening to diagnostic due to positive findings.

CRC demographics, incidence, and cancer outcomes data in the state of Kentucky were obtained through the Institutional Review Board approved collaboration with the Kentucky Cancer Registry (KCR). A data use agreement was obtained between the investigator and KCR in April 2018. The KCR is a population-based registry and has been awarded the highest level of certification by the North American Association of Central Cancer Registries for an objective evaluation of completeness, accuracy and timeliness every year since 1997. In addition, KCR is a National Cancer Institute Surveillance, Epidemiology, and End Results population-based cancer registry. The KCR also links its database annually with the State Death Certificate data and National Death Index to capture the most accurate survival information. ${ }^{17}$ The study population included all patients 20 years and older, who were diagnosed with CRC between January 1, 2011 and December 31, 2016. Only the first invasive primary CRC was included in the analysis. Cases that were captured through autopsy or death certificates were excluded. Measures obtained include demographics (age at diagnosis, sex, race, metropolitan status, Appalachian status) and insurance coverage (Medicaid, Medicare, other public insurance, private insurance and no insurance) based on payer information at the time of diagnosis from the KCR. Other variables of interest such as socioeconomics (percentage below poverty status at the county level, high school 
education ascertainment at the county level) and clinical information (tumor grade, stage at diagnosis and survival) were also included in the data analysis.

For the purpose of this study, the post-ACA implementation time period was defined as the implementation of Medicaid expansion on January 1, 2014, to December 31, 2016. The pre-ACA period was defined as an equal length of time before ACA implementation from January 1, 2011 to December 31, 2013. County of residence at time of discharge from the KHFS or time of diagnosis from the KCR were used to define patient's geographic regions. Metropolitan status was based on the 2013 Urban-Rural Continuum codes with the values of 1-3 as urban and 4-9 as rural. ${ }^{18}$ The county-level Appalachian status was defined according to the Appalachia Regional Commission, as the 54 counties in Eastern Kentucky. ${ }^{5}$ The 2008-2012 American Community Survey was used to create the poverty status and high school education ascertainment variables, which were collapsed into four levels based on the quartiles of their distributions. Poverty status is categorized as: low $(<16.2 \%)$, moderate $(16.2-18.1 \%)$, high $(18.2-21.7 \%)$, very high $(>21.7 \%)$; education ascertainment is categorized as: very low $(<75.8 \%)$, low $(75.8-84.3 \%)$, moderate (84.4-88.0\%), and high (88.1-91.8\%). Stage at diagnosis was also categorized as early (Stage I and II) and late stage (Stage III and IV). Survival was defined as length of time from date of diagnosis to death or end of the study period.

\section{Statistical Analysis}

Descriptive analysis was conducted for all variables. Chi squared tests were performed to examine the association between ACA status and other covariates, stratified by insurance status. Kaplan-Meier plots and Log-Rank tests were conducted by ACA status for each insurance type separately. Cox regression analysis was performed to determine whether ACA status is associated with survival while controlling for other variables, Goodness of fit and proportional 
hazard assumption were examined. Analyses were two-sided with a p-value $\leq 0.05$ used to identify statistical significance. All analyses were performed using SAS Statistical Software version 9.4 (SAS Institute, Inc., Cary, North Carolina, USA).

\section{RESULTS}

\section{Patient characteristics}

A total of 930,176 patients were screened for CRC from 2011 to 2016 . The highest proportion of patients screened was in 2015, and the lowest proportion screened was in 2011 (Table 1). As expected, the highest proportion of those screened were in the age 51-65 group. Interestingly, $8.2 \%$ of those screened were younger than 40 years old, which may be secondary to the high incidence of familial causes of CRC in Kentucky. ${ }^{19}$ More females were screened than males. The majority of patients who received screening were white (92.7\%) and a small proportion were black (6.0\%), which is slightly lower than the overall percentage of black patients in Kentucky (8.4\%) demonstrating a screening disparity. ${ }^{20}$ When looking at insurance coverage, nearly half of those screened had private insurance $(47.8 \%)$, while $9.7 \%$ of patients had Medicaid and $1.4 \%$ were uninsured. About a fourth of the patients who received screening were Appalachian. When looking specifically at the Medicaid subgroup, higher proportion of female (62.6\%) and black patients $(9.6 \%)$ received screening compared to all insurance types. Nearly half of the Medicaid patients who received screening were Appalachian (42.3\%).

\section{Impact of ACA Expansion on CRC Screening}

A total of 408,500 patients were screened pre-ACA and 521,676 were screened after ACA implementation, an increase of $27.7 \%$ (Table 2). Colonoscopy was utilized as the major 
screening method in $72.7 \%$ of patients. The $51-65$ age group had the highest increase in screening, while both sexes increased proportionally. When comparing screening rates based on insurance coverage, patients with Medicaid demonstrated the highest increase in CRC screening. A total of 69,328 Medicaid patients received screening after ACA implementation compared to 20,980 individuals who were screened pre-ACA, thus representing an increase of $230 \%$. Screening rates for patients with private insurance increased by $10.2 \%$ and Medicare patients increased by $29.9 \%$. Overall, 43.7\% more Appalachian patients received CRC screening after ACA implementation compared to pre-ACA.

When looking specifically at Medicaid patients, individuals in the 51-65 age group had the highest improvement in screening $(+292.5 \%)$. There was also a higher proportional increase in screening in males compared to females after ACA implementation. The increase of coverage in all races remained proportional. Similar to the overall Kentucky trend, Medicaid coverage of Appalachian patients increased by $199.0 \%$ while uninsured Appalachian patients decreased by 77.7\% after ACA implementation (Figure 1).

\section{Impact of ACA Expansion on CRC Incidence}

From January 1, 2011 to December 31, 2016, 11,441 Kentucky patients were diagnosed with CRC. After ACA Medicaid expansion, there was not a significant increase in incidence (5,665 pre-ACA vs. 5,776 after ACA implementation), but there was a change in the distribution (Table 3). The CRC incidence in the $20-49$ age group increased by $22.8 \%$, while the age $75-90$ group decreased by $7.5 \%$, indicating a shift toward an increase in incidence in the younger population consistent with national CRC trends. ${ }^{21}$ When separated by insurance, the proportion 
of Medicaid patients who were diagnosed with CRC increased by $132.4 \%$ after Medicaid expansion. In patients who had Medicaid, there were no significant differences in regard to poverty and education level indicating a similar population before and after ACA implementation. Consequently, there was a four-fold decrease in incidence in the uninsured group.

When evaluating patients who had Medicaid coverage, there was an increase in Appalachian CRC incidence (87.8\%) (Figure 2). When separating out incidence by stage in this group, the proportion of early stage diagnoses (stage I/II) increased by $9.3 \%$ for Appalachians ( $\mathrm{p}=0.09$ ), which was not noted in non-Appalachians $(-1.5 \%, \mathrm{p}=0.60)$. There was no effect on late stage diagnosis.

\section{Impact of ACA Expansion on CRC Survival}

When evaluating the role of ACA expansion in CRC survival, both Medicaid and Appalachian patients benefited while uninsured patients suffered. After ACA implementation, Medicaid patients exhibited improved survival compared to patients prior to instituting ACA (Figure 3). Conversely, the remaining uninsured patients who did not receive coverage from ACA implementation had a worse survival compared to pre-ACA implementation. There were no significant differences in survival for private insurance and Medicare with regards to ACA expansion. Notably, the survival differences after ACA implementation was evident in Medicaid patients after the first year and increased each year thereafter (eTable 1). We noted an overall worse survival (HR 2.12, 95\%, CI 1.23-3.67, $\mathrm{p}=0.048)$ in the black uninsured population compared with the white population, consistent with national trends. ${ }^{22}$ This effect was not seen in any other insurance groups. 
When controlling for age, sex, race, cancer stage and grade, cox regression analysis revealed all Medicaid patients had improved survival after ACA implementation compared to pre-ACA implementation (HR 0.73, 95\% CI 0.58-2.11; $\mathrm{p}=0.008$ ). Interestingly, when looking specifically at Appalachian patients with Medicaid coverage, there was significantly improved survival after ACA implementation compared to the period pre-ACA (Figure 4). However, there was no difference in survival in the Medicaid non-Appalachian population, indicating the improvement in overall Medicaid patient survival after ACA implementation was heavily contributed by the Appalachian population.

\section{DISCUSSION}

ACA Medicaid expansion has had unprecedented success in providing Medicaid coverage for the uninsured population in Kentucky. Earlier studies demonstrated implementation of the expansion increased screening in prostate cancer, ${ }^{23}$ cervical cancer, ${ }^{24-26}$ and breast cancer. ${ }^{25,27}$ In Kentucky, improved coverage was also associated with earlier diagnosis of breast cancer and improved treatment quality. ${ }^{27}$ We set out to evaluate the impact of ACA expansion on CRC screening. We found the expansion of Medicaid in Kentucky significantly increased CRC screening, particularly in the Appalachian population. Moreover, ACA expansion was associated with increased CRC incidence in the Medicaid population with a shift toward early stage diagnosis in Appalachian patients. Importantly, we demonstrated for the first time that ACA expansion significantly increased CRC survival in both the Medicaid and Kentucky Appalachian populations. 
Our study established the substantial impact of insurance coverage in amplifying CRC screening. Over the past two decades, Kentucky has implemented several programs to expand CRC screening. ${ }^{15}$ The major barriers to CRC screening include lack of insurance coverage and lack of provider recommendation. ${ }^{6-8,28,29}$ Our study demonstrated the ACA Medicaid expansion decreased the number of low-income uninsured patients in Kentucky which help to alleviate barriers to healthcare access. By 2015, in the second year of expansion, there was $12 \%$ increased access to PCPs, allowing greater than $85 \%$ of low-income patients to easily obtain physician visits. ${ }^{30}$ Improved healthcare system contact led to increased preventative screening by enabling access to PCPs. ${ }^{9}$ The Behavioral Risk Factor Surveillance System reported in 1999 the CRC screening rate in Kentucky was $34.7 \%$ compared to $43.9 \%$ nationally. CRC screening plateaued just before ACA implementation at 65.7\%. After ACA implementation in 2014, screening in Kentucky further increased to $69.6 \%$ compared to $66.6 \%$ nationally. ${ }^{14,31}$ However, Appalachian Kentucky screening lagged behind, at $63.0 \%{ }^{2}$ The most recent 2016 data revealed further improvement of screening rates to $70.1 \%$ compared to $67.7 \%$ nationally. ${ }^{14,31}$ Similarly, we identified a more than threefold increase in CRC screening three years after Medicaid expansion. In Kentucky, additional insurance coverage increased CRC incidence immediately after ACA implementation. CRC incidence has steadily decreased over the past 40 years. ${ }^{32,33}$

Microsimulation models suggest the largest contribution come from screening, while risk factor reduction and treatment improvements are minor contributors. ${ }^{33,34}$ Early detection of precursor lesions would have immediate reduction of CRC incidence within the first two years and maximal reduction by 15 years. ${ }^{32,34-38}$ We would expect immediate increased incidence in newly insured Medicaid patients as existing cancers are identified. In addition, this population may also have a shift toward earlier stage diagnosis. ${ }^{39,40}$ However, as expected, the removal of pre- 
cancerous lesions would decrease cancer progression leading to decreased incidence rates. ${ }^{11}$ Similarly, we identified an increase of incidence in the Medicaid and Appalachian population immediately after ACA implementation. We demonstrated a trend toward higher rates of early stage (I and II) CRC diagnosis in the Appalachian population, which was not seen in the uninsured population. Because this study evaluated the short-term effects of Medicaid expansion, we would not expect a decrease in CRC incidence.

CRC screening is very effective in reducing the cancer specific mortality risk. Zauber et al ${ }^{12}$ demonstrated a $53 \%$ reduction of 10 -year survival in patients who received a screening colonoscopy. In fact, the impact of CRC screening on survival continues for up to two decades. ${ }^{41}$ Even so, CRC mortality in Kentucky remain behind national standards. In 2011-2015 the mortality rate of CRC nationally was 14.5 per 100,000 compared to 17.0 per 100,000 in the state of Kentucky. ${ }^{2}$ Appalachian Kentucky mortality was even higher, with a more profound benefit from screening. ${ }^{42,43}$ In just a short time interval After ACA implementation, we showed that Medicaid patients had a $27 \%$ lower risk of death compared to pre-ACA, while those who were uninsured had an overall worse survival. Notably, the Kentucky Appalachian patients also had a significantly improved survival associated with the dramatic expansion of Medicaid coverage as a result of increased CRC screening.

We demonstrated a markedly improved survival in both the Medicaid and Kentucky Appalachian population in just a short time after ACA implementation. In fact, the significant survival improvement was evident within the first year. Similarly, several studies including a large metanalysis demonstrated a survival difference at 3 years after receiving CRC screening, with the maximal effect at 15 years. ${ }^{44,45}$ The short term effects of a CRC screening program implementation on survival was also found in a Kaiser Permanente health system demonstrating 
a significant decrease in mortality within 4 years. ${ }^{11}$ Our survival follow-up time was greater than 6 years for the pre-ACA group and greater than 4 years for the after ACA implementation group. As CRC incidence can drop within two years after improved screening, survival differences can be seen within our follow up time period partly due to early detection and treatment. ${ }^{35}$ Importantly, the improved survival after ACA implementation was not evident in the private, Medicare and uninsured populations, indicating the specific association of survival after CRC screening with Medicaid patients.

The results of this study could be generalized to other states that have expanded Medicaid coverage. Nonetheless, there are several limitations to our current study. The CRC screening data may contain a small number of patients who underwent more than one screening procedure, thus was counted twice. However, it is extremely unlikely for a second procedure to be coded as a screening procedure, and more likely to be coded as a diagnostic procedure. In addition, prior to 2016, post-hoc manipulation of CPT codes was legal. As a result, there may be a bias among the colonoscopies that had CPT codes converted from screening to diagnostic as a result of a positive finding during the procedure. This would have underestimated screening colonoscopies before 2016. Next, the significant survival benefit identified in the Medicaid population after ACA implementation may be contributed by other factors which were not included in the analysis. For example, prior to ACA implementation, only the most impoverished adults (less than half of FPL) were covered by Medicaid, whereas after implementation, the coverage included up to $138 \%$ of the FPL. This higher income group were likely more health conscious and had better access to care, which was evident by the decreased survival in the uninsured population, suggesting only patients with the lowest level of access remain uninsured after ACA implementation. However, these individual socioeconomic and health access factors were not 
available for the data analysis. Lastly, cancer survival is also related to reliable quality treatment, which is not accounted in our survival analysis. However, due to our demonstration of improvement in survival post-ACA, poor quality treatment would unlikely effect our results negatively.

\section{CONCLUSIONS}

CRC incidence and mortality in Kentucky is one of the highest in the United States. ACA Medicaid expansion has positively affected insurance coverage in this population leading to improved CRC screening and improved short-term survival. Future long-term survival studies are needed, but the short-term benefits of the ACA expansion have bridged a gap in CRC disparities in Kentucky.

\section{ACKNOWLEDGEMENT}

We would like to acknowledge and thank the Markey Cancer Center Biostatistics and Bioinformatics Shared Resource Facility for statistical analyses, as well as the Center for Clinical and Translational Sciences for assistance with data extraction. We would also like to thank the Cancer Research Information Shared Resource Facility for obtaining Kentucky colorectal cancer patient data and analysis from the Kentucky Cancer Registry. Lastly, we would like to thank the University of Kentucky Research Communications Office for the aid in figure preparation for the manuscript. 


\section{References}

1. Cancer Statistics Center. 2018; https://cancerstatisticscenter.cancer.org. Accessed October 8, 2018.

2. Rodriguez SD, Vanderford NL, Huang B, Vanderpool RC. A Social-Ecological Review of Cancer Disparities in Kentucky. Southern Med J 2018;111:213-219.

3. Stats of the State of Kentucky. Centers for Disease Control and Prevention. 2016; https://www.cdc.gov/nchs/pressroom/states/kentucky.htm. Accessed October 8, 2018.

4. Bureau USC. Income and Poverty in the United States: 2017. 2018; https://www.census.gov/topics/income-poverty/data/tables.html. Accessed October 4, 2018. 5. County Economic Status, Fiscal Year 2019. 2018; https://www.arc.gov/reports/custom_report.asp?REPORT_ID=75. Accessed September 25, 2018.

6. Meissner HI, Klabunde CN, Breen N, Zapka JM. Breast and colorectal cancer screening: U.S. primary care physicians' reports of barriers. Am J Preventive Med 2012;43:584-589.

7. Knight JR, Kanotra S, Siameh S, et al. Understanding barriers to colorectal cancer screening in Kentucky. Preventing Chronic Dis 2015;12:E95.

8. John M. Bennett M, Sarojini K, et al. Barriers to colon cancer screening in Kentucky. J Kentucky Med Assoc 2011;109.

9. Benitez JA, Creel L, Jennings J. Kentucky's Medicaid Expansion showing early promise on coverage and access to care. Health Affairs 2016;35:528-534.

10. Study of the Impact of the ACA Implementation in Kentucky. 2017; https://www.healthy-ky.org/res/images/resources/Impact-of-the-ACA-in-KY_FINALReport.pdf. Accessed October 9, 2018. 
11. Levin TR, Corley DA, Jensen CD, et al. Effects of organized colorectal cancer screening on cancer incidence and mortality in a large, community-based population. Gastroenterol 2018. 12. Zauber AG, Winawer SJ, O'Brien MJ, et al. Colonoscopic polypectomy and long-term prevention of colorectal-cancer deaths. N Engl J Med 2012;366:687-696.

13. Final Recommendation Statement: Colorectal Cancer: Screening. 2014; https://www.uspreventiveservicestaskforce.org/Page/Document/RecommendationStatementFinal /colorectal-cancer-screening. Accessed September 11, 2018.

14. BRFSS Prevalence \& Trends Data. 2015; https://www.cdc.gov/brfss/brfssprevalence/. Accessed September 10, 2018.

15. Kentucky Colon Cancer Screening Program Annual Report 2013 - 2014, Kentucky Department for Public Health, Chronic Disease Prevention Branch. 2014; https://chfs.ky.gov/agencies/dph/dpqi/cdpb/Documents/KYColonCancer20132014Annual.pdf. Accessed October 8, 2018.

16. Colorectal Cancer Facts \& Figures 2014-2016. American Cancer Society. https://www.cancer.org/content/dam/cancer-org/research/cancer-facts-and-statistics/colorectalcancer-facts-and-figures/colorectal-cancer-facts-and-figures-2014-2016.pdf. Accessed October 9, 2018.

17. About the Kentucky Cancer Registry. Kentucky Cancer Registry. https://www.kcr.uky.edu/about.php. Accessed September 18, 2018.

18. Parker T. Rural-Urban Continuum Codes. 2016; https://www.ers.usda.gov/dataproducts/rural-urban-continuum-codes. Accessed October 8, 2018.

19. Clendenning M, Baze ME, Sun S, et al. Origins and prevalence of the American Founder Mutation of MSH2. Cancer Res 2008;68:2145-2153. 
20. United States Census Bureau Quick Facts Kentucky. 2017;

https://www.census.gov/quickfacts/ky. Accessed October 8, 2018.

21. Siegel RL, Fedewa SA, Anderson WF, et al. Colorectal Cancer Incidence Patterns in the United States, 1974-2013. JNCI: J Nat Cancer Inst 2017;109:djw322-djw322.

22. Alexander DD, Waterbor J, Hughes T, et al. African-American and Caucasian disparities in colorectal cancer mortality and survival by data source: an epidemiologic review. Cancer biomarkers : section A of Disease markers 2007;3:301-313.

23. Sammon JD, Serrell EC, Karabon P, et al. Prostate cancer screening in early Medicaid Expansion states. J Urology 2018;199:81-88.

24. Choi SK, Adams SA, Eberth JM, et al. Medicaid Coverage Expansion and implications for cancer disparities. Am J Public Health 2015;105:S706-712.

25. Sabik LM, Tarazi WW, Bradley CJ. State Medicaid expansion decisions and disparities in women's cancer screening. Am J Preventive Med 2015;48:98-103.

26. Hendryx M, Luo J. Increased cancer screening for low-income adults under the Affordable Care Act Medicaid Expansion. Med Care 2018;56:944-949.

27. Ajkay N, Bhutiani N, Huang B, et al. Early impact of Medicaid Expansion and quality of breast cancer care in Kentucky. J Am Coll Surg 2018;226:498-504.

28. Vital signs: colorectal cancer screening test use--United States, 2012. MMWR Morbidity Mortality Weekly Rep 2013;62:881-888.

29. Jones RM, Devers KJ, Kuzel AJ, Woolf SH. Patient-reported barriers to colorectal cancer screening: a mixed-methods analysis. Am J Preventive Med 2010;38:508-516. 
30. Sommers BD, Blendon RJ, Orav EJ, Epstein AM. Changes in utilization and health among low-income adults after Medicaid Expansion or expanded private insurance. JAMA Int Med 2016;176:1501-1509.

31. Tucker TN, J. Uses of Central Cancer Registry Data. In: Mench H GD, Griffin A, Mulvihill L, et al. Cancer Registry Management Principles and Practice. Kendall Hunt Publishing; 2011.

32. Murphy CC, Sandler RS, Sanoff HK, et al. Decrease in incidence of colorectal cancer among individuals 50 years or older after recommendations for population-based screening. Clin Gastroenterol Hepatol 2017;15:903-909.e906.

33. Edwards BK, Ward E, Kohler BA, et al. Annual report to the nation on the status of cancer, 1975-2006, featuring colorectal cancer trends and impact of interventions (risk factors, screening, and treatment) to reduce future rates. Cancer 2010;116:544-573.

34. Wolf AMD, Fontham ETH, Church TR, et al. Colorectal cancer screening for averagerisk adults: 2018 guideline update from the American Cancer Society. CA 2018;68:250-281.

35. Atkin WS, Edwards R, Kralj-Hans I, et al. Once-only flexible sigmoidoscopy screening in prevention of colorectal cancer: a multicentre randomised controlled trial. Lancet 2010;375:1624-1633.

36. Zauber AG. The impact of screening on colorectal cancer mortality and incidence: has it really made a difference? Dig Dis Sciences 2015;60:681-691.

37. Brenner $\mathrm{H}$, Hoffmeister M, Arndt V, et al. Protection from right- and left-sided colorectal neoplasms after colonoscopy: population-based study. J Nat Cancer Inst 2010;102:89-95.

38. Singh $\mathrm{H}$, Nugent $\mathrm{Z}$, Demers AA, et al. The reduction in colorectal cancer mortality after colonoscopy varies by site of the cancer. Gastroenterology 2010;139:1128-1137. 
39. Soni A, Simon K, Cawley J, Sabik L. Effect of Medicaid Expansions of 2014 on overall and early-stage cancer diagnoses. Am J Public Health 2018;108:216-218.

40. Jemal A, Lin CC, Davidoff AJ, Han X. Changes in insurance coverage and stage at diagnosis among nonelderly patients with cancer after the Affordable Care Act. J Clin Oncol 2017;35:3906-3915.

41. Chen C, Stock C, Hoffmeister M, Brenner H. How long does it take until the effects of endoscopic screening on colorectal cancer mortality are fully disclosed?: A Markov model study. Int J Cancer 2018.

42. Mark Dignan EP, Eugene Lengerich. The cancer burden in Appalachia 2009. 2009; www.accnweb.com/docs/CancerBurdenAppalachia2009.pdf. Accessed 9-10-18.

43. Seiber EE, Camacho F, Zeeshan MF, et al. Disparities in colorectal cancer treatment delay within Appalachia - the role of for-profit hospitals. J Rural Health 2015;31:382-391. 44. Tang V, Boscardin WJ, Stijacic-Cenzer I, Lee SJ. Time to benefit for colorectal cancer screening: survival meta-analysis of flexible sigmoidoscopy trials. BMJ 2015;350:h1662-h1662. 45. Lee SJ, Boscardin WJ, Stijacic-Cenzer I, et al. Time lag to benefit after screening for breast and colorectal cancer: meta-analysis of survival data from the United States, Sweden, United Kingdom, and Denmark. BMJ 2013;346:e8441. 
Table 1. Patient Demographics.

\begin{tabular}{|c|c|c|}
\hline Patient characteristic & $\mathbf{n}$ & $\%$ \\
\hline \multicolumn{3}{|c|}{ All Kentucky patients, 2011-2016, $n=930,176$} \\
\hline \multicolumn{3}{|c|}{ ACA Status } \\
\hline Pre-ACA* & 408,500 & 43.9 \\
\hline Post-ACA & 521,676 & 56.1 \\
\hline \multicolumn{3}{|l|}{ Year screened } \\
\hline 2011 & 124,049 & 13.3 \\
\hline 2012 & 142,166 & 15.3 \\
\hline 2013 & 142,285 & 15.3 \\
\hline 2014 & 151,956 & 16.3 \\
\hline 2015 & 194,406 & 20.9 \\
\hline 2016 & 175,314 & 18.9 \\
\hline \multicolumn{3}{|l|}{ Age } \\
\hline $20-40 y$ & 75,923 & 8.2 \\
\hline $41-50 y$ & 129,050 & 13.9 \\
\hline $51-65 y$ & 422,588 & 45.4 \\
\hline $66-70 y$ & 118,714 & 12.8 \\
\hline$>71 \mathrm{y}$ & 183,901 & 19.8 \\
\hline \multicolumn{3}{|l|}{ Sex } \\
\hline Female & 517,830 & 55.7 \\
\hline Male & 412,346 & 44.3 \\
\hline \multicolumn{3}{|l|}{ Race } \\
\hline White & 862,144 & 92.7 \\
\hline Black & 55,742 & 6.0 \\
\hline Other & 12,290 & 1.3 \\
\hline \multicolumn{3}{|l|}{ Insurance } \\
\hline Not Insured & 14,064 & 1.5 \\
\hline Private & 444,794 & 47.8 \\
\hline Medicare & 367,974 & 39.6 \\
\hline Medicaid & 90,308 & 9.7 \\
\hline Other public ${ }^{\dagger}$ & 13,036 & 1.4 \\
\hline \multicolumn{3}{|l|}{ Stage } \\
\hline 1 & 2,444 & 21.8 \\
\hline II & 2,600 & 23.2 \\
\hline III & 2,789 & 24.9 \\
\hline IV & 2,224 & 19.8 \\
\hline Unknown & 1,152 & 10.3 \\
\hline \multicolumn{3}{|l|}{ Appalachian Status } \\
\hline Non-Appalachian & 682,545 & 73.4 \\
\hline
\end{tabular}




\begin{tabular}{|c|c|c|}
\hline Appalachian & 247,631 & 26.6 \\
\hline \multicolumn{3}{|c|}{ Medicaid patients only, 2011-2016, $n=90,308$} \\
\hline \multicolumn{3}{|c|}{ ACA Status } \\
\hline Pre-ACA* & 20,980 & 23.2 \\
\hline Post-ACA & 69,328 & 76.8 \\
\hline \multicolumn{3}{|l|}{ Year screened } \\
\hline 2011 & 6,606 & 733 \\
\hline 2012 & 7,282 & 8.1 \\
\hline 2013 & 7,092 & 7.8 \\
\hline 2014 & 20,394 & 22.6 \\
\hline 2015 & $27,772(30.8 \%)$ & 30.8 \\
\hline 2016 & $21,162(23.4 \%)$ & 23.4 \\
\hline \multicolumn{3}{|l|}{ Age } \\
\hline $20-40 y$ & 19,762 & 21.9 \\
\hline $41-50 y$ & 21,052 & 23.3 \\
\hline $51-65$ y & 48,151 & 53.3 \\
\hline $66-70 y$ & 664 & 0.7 \\
\hline$>71 \mathrm{y}$ & 679 & 0.8 \\
\hline \multicolumn{3}{|l|}{ Sex } \\
\hline \begin{tabular}{l|l} 
Female \\
\end{tabular} & 56,510 & 62.6 \\
\hline Male & 33,798 & 37.4 \\
\hline \multicolumn{3}{|l|}{ Race } \\
\hline White & 79,798 & 88.4 \\
\hline Black & 8,661 & 9.6 \\
\hline Other & 1,849 & 2.0 \\
\hline \multicolumn{3}{|l|}{ Appalachian Status } \\
\hline Non-Appalachian & 52,112 & 57.7 \\
\hline Appalachian & 38,196 & 42.3 \\
\hline \multicolumn{3}{|l|}{ Stage } \\
\hline 1 & 195 & 19.7 \\
\hline II & 207 & 20.9 \\
\hline III & 237 & 24.0 \\
\hline IV & 255 & 25.8 \\
\hline Unknown & 95 & 9.6 \\
\hline
\end{tabular}

*Pre-Affordable Care Act (ACA) from 2011 to 2013, post-ACA from 2014-2016.

†Includes TRICARE, Veterans Affairs, and Military insurances. 
Table 2. Bivariate Analysis of Pre-Affordable Care Act and Post-Affordable Care Act of Colorectal Cancer Screening

\begin{tabular}{|c|c|c|c|}
\hline \multirow[b]{2}{*}{$\begin{array}{l}\text { Patient } \\
\text { characteristic }\end{array}$} & \multicolumn{2}{|c|}{ Colorectal cancer screening, n (\%) } & \multirow[b]{2}{*}{ p Value } \\
\hline & Pre-ACA ${ }^{*}, n=408,500$ & Post-ACA, $n=521,676$ & \\
\hline Age & & & $<0.0001$ \\
\hline $20-40 y$ & $36,002(8.8)$ & $39,921(7.7)$ & \\
\hline $41-50$ y & $59,825(14.7)$ & $69,225(13.3)$ & \\
\hline $51-65$ y & $182,362(44.6)$ & $240,226(46.0)$ & \\
\hline $66-70$ y & $50,355(12.3)$ & $68,359(13.1)$ & \\
\hline$>71 \mathrm{y}$ & $79,956(19.6)$ & $103,945(19.9)$ & \\
\hline Sex & & & $<0.0001$ \\
\hline Female & $228,830(56.0)$ & $289,000(55.4)$ & \\
\hline Male & $179,670(44.0)$ & $232,676(44.6)$ & \\
\hline Race & & & $<0.0001$ \\
\hline White & $379,190(93)$ & $482,954(93)$ & \\
\hline Black & $23,817(6)$ & $39,125(6)$ & \\
\hline Other & $5,493(1)$ & $6,797(1)$ & \\
\hline Insurance & & & $<0.0001$ \\
\hline Uninsured & $10,617(2.6)$ & $3,447(0.7)$ & \\
\hline Private & $211,618(51.8)$ & $233,176(44.7)$ & \\
\hline Medicare & $160,027(39.2)$ & $207,947(39.8)$ & \\
\hline Medicaid & $20,980(5.1)$ & $69,328(13.3)$ & \\
\hline Other public ${ }^{\dagger}$ & $5,258(1.3)$ & $7,778(1.5)$ & \\
\hline Appalachian status & & & $<0.0001$ \\
\hline No & $306,880(75.1)$ & $375,665(72.0)$ & \\
\hline Yes & $101,620(24.9)$ & $146,011(28.0)$ & \\
\hline
\end{tabular}

*Pre-Affordable Care Act (ACA) from 2011 to 2013, post-ACA from 2014-2016.

†Includes TRICARE, Veterans Affairs, and Military insurances. 
Table 3. Bivariate Analysis of Pre-Affordable Care Act and Post-Affordable Care Act of

Colorectal Cancer Incidence Separated by All Insurance Types and Medicaid Only.

\begin{tabular}{|c|c|c|c|}
\hline $\begin{array}{c}\text { Patient } \\
\text { characteristic }\end{array}$ & Pre-ACA ${ }^{*}(n=5,665), n(\%)$ & Post-ACA ( $n=5,776), n(\%)$ & p Value \\
\hline \multicolumn{4}{|l|}{ All insurance types } \\
\hline Age & & & $<0.001$ \\
\hline $20-49$ y & $648(11.4)$ & $796(13.8)$ & \\
\hline $50-64$ y & $2,005(35.4)$ & $2,072(35.9)$ & \\
\hline $65-74$ y & $1,456(25.7)$ & $1,468(25.4)$ & \\
\hline$\geq 75 y$ & $1,556(27.5)$ & $1,440(24.9)$ & \\
\hline Sex & & & 0.915 \\
\hline Female & $2,641(46.6)$ & $2,687(46.5)$ & \\
\hline Male & $3,024(53.4)$ & $3,089(53.5)$ & \\
\hline Race & & & 0.007 \\
\hline White & $5,237(92.4)$ & $5,302(91.8)$ & \\
\hline Black & $365(6.5)$ & $368(6.4)$ & \\
\hline Other & $63(1.1)$ & $106(1.8)$ & \\
\hline Insurance & & & $<0.001$ \\
\hline Uninsured & $310(5.5)$ & $67(1.2)$ & \\
\hline Private & $1,788(31.5)$ & $1,810(31.3)$ & \\
\hline Medicare & $3,001(53.0)$ & $2,964(51.3)$ & \\
\hline Medicaid & $299(5.3)$ & $695(12.0)$ & \\
\hline Other Public ${ }^{\dagger}$ & $267(5.7)$ & $240(4.2)$ & \\
\hline \multicolumn{2}{|l|}{ Appalachian status } & & 0.131 \\
\hline No & $3,888(68.6)$ & $3,888(67.3)$ & \\
\hline Yes & $1,777(31.4)$ & $1,888(32.7)$ & \\
\hline \multicolumn{2}{|l|}{ Tumor grade } & & $<0.001$ \\
\hline \begin{tabular}{l|l} 
Well- \\
differentiated
\end{tabular} & $265(4.7)$ & $437(7.6)$ & \\
\hline $\begin{array}{l}\text { Moderately- } \\
\text { differentiated }\end{array}$ & $3731(65.9)$ & $3735(64.6)$ & \\
\hline $\begin{array}{l}\text { Poorly- } \\
\text { differentiated }\end{array}$ & $424(7.5)$ & $439(7.6)$ & \\
\hline $\begin{array}{l}\text { Undifferentiate } \\
\text { d }\end{array}$ & $466(8.2)$ & $425(7.4)$ & \\
\hline \begin{tabular}{l|l} 
Unknown \\
\end{tabular} & 779 (13.7) & $740(12.8)$ & \\
\hline \multicolumn{4}{|l|}{ Medicaid only } \\
\hline Age & & & 0.003 \\
\hline \begin{tabular}{l|l}
$20-49 y$ \\
\end{tabular} & $78(26.1)$ & 220 (31.7) & \\
\hline
\end{tabular}




\begin{tabular}{|c|c|c|c|}
\hline $50-64$ y & $183(61.1)$ & $433(62.3)$ & \\
\hline $65-74$ y & $19(6.4)$ & $23(3.3)$ & \\
\hline $75-90 y$ & $19(6.4)$ & $19(2.7)$ & \\
\hline Sex & & & 0.059 \\
\hline Female & $152(50.8)$ & $308(44.3)$ & \\
\hline Male & $147(49.2)$ & $387(55.7)$ & \\
\hline Race & & & 0.633 \\
\hline White & $268(89.6)$ & $603(86.8)$ & \\
\hline Black & $28(9.4)$ & $83(11.9)$ & \\
\hline Other & $3(1.0)$ & $9(1.3)$ & \\
\hline \multicolumn{2}{|c|}{ Appalachian status } & & 0.008 \\
\hline No & $160(53.5)$ & $434(62.5)$ & \\
\hline Yes & $139(46.5)$ & $261(37.5)$ & \\
\hline \multicolumn{2}{|l|}{ Poverty level $^{\ddagger}$} & & 0.072 \\
\hline \begin{tabular}{l|l} 
Low \\
\end{tabular} & $51(17.1)$ & $148(21.3)$ & \\
\hline Moderate & $62(20.7)$ & $166(23.9)$ & \\
\hline High & $72(24.1)$ & $172(24.7)$ & \\
\hline Very High & $114(38.1)$ & $209(30.1)$ & \\
\hline \multicolumn{2}{|c|}{ High school education§ } & & 0.084 \\
\hline Very Low & $121(40.5)$ & $217(31.2)$ & \\
\hline Low & $69(23.1)$ & $167(24.0)$ & \\
\hline Moderate & $85(28.4)$ & $237(34.1)$ & \\
\hline High & $24(8.0)$ & $74(10.7)$ & \\
\hline
\end{tabular}

*Pre-Affordable Care Act (ACA) from 2011 to 2013, post-ACA from 2014-2016.

'Includes TRICARE, Veterans Affairs, and Military insurances.

‡Low, \% under poverty level $\leq 16.2$; Moderate, \% under poverty level 16.3-18.1; High, \% under poverty level 18.221.7; Very High, $\%$ under poverty level $\geq 21.8$.

$\S$ Very Low, \% completed high school $\leq 75.8$; Low, \% completed high school 75.9-84.4; Moderate, \% completed high school 84.5-88.1; High, \% completed high school $\geq 88.2$. 


\section{FIGURE LEGENDS:}

Figure 1. Colorectal cancer (CRC) screening by insurance and Appalachian (App) status. CRC screening data were obtained from Kentucky Cabinet for Health and Family Services from January 1, 2011 to December 31, 2016. (A) All screening cases were separated by insurance status depending on pre-Affordable Care Act (ACA) (screening obtained in 2011 to 2013) or post-ACA status (screening obtained in 2013-2016). (B) Patients with Medicaid coverage who received screening were separated by Appalachian and non-Appalachian status and compared pre- and post-ACA implementation.

Figure 2. Colorectal cancer (CRC) incidence by insurance and Appalachian (App) status. CRC incidence from January 1, 2011 to December 31, 2016 was obtained from the Kentucky Cancer Registry. Pre-ACA was defined as the time period from 2011 to 2013 while post-ACA was from 2014 to 2016. (A) All cases of CRC were separated out by insurance types and compared before and after ACA implementation. (B) Incidence rates of CRC were compared in all Medicaid patients separated by Appalachian and non-Appalachian status.

Figure 3. Colorectal cancer (CRC) survival after Affordable Care Act (ACA) by insurance type. Survival analysis was performed via Kaplan Meier plots. Pre-ACA was defined as the time period between 2011 and 2013, and post-ACA was defined as the time period between 2014 and 2016. All CRC cases were separated by insurance status: (A) private; (B) Medicaid; (C) Medicare; and (D) no insurance. 
Figure 4. Colorectal cancer (CRC) survival for Medicaid patients after Affordable Care Act (ACA) by Appalachian status. Medicaid patients who were diagnosed with CRC were identified in the Kentucky Cancer Registry from January 1, 2011 to December 31, 2016. Survival analysis was performed with Kaplan Meier plots to evaluate survival in the (A) non-Appalachian and (B) Appalachian population. 


\section{Precis}

Kentucky was an early adopter of the Affordable Care Act Medicaid Expansion, providing a significant amount of insurance coverage for poor individuals. As a result, Kentucky had increased colorectal cancer screening, earlier diagnosis, and improved survival, especially evident in Medicaid and Appalachian patients. 